Journal of Mathematics and Statistics 4 (2): 112-116, 2008

ISSN 1549-3644

(C) 2008 Science Publications

\title{
Some Subordination Results Associated With Certain Subclass of Analytic Meromorphic Functions
}

\author{
F. Ghanim and M. Darus \\ School of Mathematical Sciences, Faculty of Science and Technology, \\ Universiti Kebangsaan Malaysia, Bangi 43600 Selangor D. Ehsan, Malaysia
}

\begin{abstract}
For functions belonging to each of the subclasses $S^{*}{ }_{w}(\beta)$ and $C^{*}{ }_{w}(\beta)$ of normalized analytic functions in the open unit disk $\mathrm{D}$, which are investigated in this paper when $0 \leq \beta<1$, the authors derive several subordination results involving the Hadamard product (or convolution) of the associated functions. A number of interesting consequences of some of these subordination results are also discussed.
\end{abstract}

Key words: Univalent functions, convex functions, subordination principle, hadamard product (or convolution), subordinating factor sequence

\section{INTRODUCTION}

Let $\mathrm{A}$ be the class of functions f normalized by:

$$
f(z)=z+\sum_{n=1}^{\infty} a_{n} z^{n}
$$

which are analytic in the open unit disk $D=\{z \in C:|z| \leq 1\}$.

As usual, we denote by $\mathrm{S}$ he subclass of $\mathrm{A}$, consisting of functions which are also univalent in D. We recall here the definitions of the well-known classes of starlike function and convex functions:

$$
\begin{aligned}
& S^{*}=\left\{f \in A: \operatorname{Re}\left(\frac{z f^{\prime}(z)}{f(z)}\right)>0, z \in D\right\}, \\
& C^{*}=\left\{f \in A: \operatorname{Re}\left(1+\frac{z f^{\prime \prime}(z)}{f^{\prime}(z)}\right)>0, z \in D\right\},
\end{aligned}
$$

Let $\mathrm{w}$ be a fixed point in $\mathrm{D}$ and $\mathrm{A}(\mathrm{w})=\{\mathrm{f} \in \mathrm{H}(\mathrm{D})$ : $\left.\mathrm{f}(\mathrm{w})=\mathrm{f}^{\prime}(\mathrm{w})-1=0\right\}$.

$\mathrm{In}^{[15]}$, Kanas and Ronning introduced the following classes $S_{\mathrm{w}}=\{\mathrm{f} \in \mathrm{A}(\mathrm{w}): \mathrm{f}$ is univalent in $\mathrm{D}\}$ $\mathrm{C}_{\mathrm{W}}^{*}=\left\{\mathrm{f} \in \mathrm{A}(\mathrm{w}): \operatorname{Re}\left(1+\frac{(\mathrm{z}-\mathrm{w}) \mathrm{f}^{\prime \prime}(\mathrm{z})}{\mathrm{f}^{\prime}(\mathrm{z})}\right)>0, \mathrm{z} \in \mathrm{D}\right\}$. Late $\mathrm{r}$ Acu and $\mathrm{Owa}^{[1]}$ studied the classes extensively.

Let $\mathrm{S}_{\mathrm{W}}$ denoted the subclass of $\mathrm{A}(\mathrm{w})$ consisting of the function of the form:

$$
f(z)=\frac{\alpha}{z-w}+\sum_{n=1}^{\infty} a_{n}(z-w)^{n}
$$

$\left(a_{n} \geq 0, z \in D\right)$. where $\alpha=\operatorname{Res}(z, w), 0<\alpha \leq 1$ with $z \neq w$.

The class $\mathrm{s}_{\mathrm{w}}^{*}$ is defined by geometric property that the image of any circular arc centered at $\mathrm{w}$ is starlike with respect to $\mathrm{f}(\mathrm{w})$ and the corresponding class $\mathrm{C}_{\mathrm{w}}{ }_{\mathrm{w}}$ is defined by the property that the image of any circular arc centered at $\mathrm{w}$ is convex.

We observe that the definitions are somewhat similar to the ones introduced by Goodman in ${ }^{[13,14]}$ for uniformly starlike and convex functions, except that in this case the point $w$ is fixed.

The functions $f(z)$ in $S_{w}$ is said to be starlike functions of order $\beta$ if and only if:

$$
\operatorname{Re}\left\{\frac{(\mathrm{z}-\mathrm{w}) \mathrm{f}^{\prime}(\mathrm{z})}{\mathrm{f}(\mathrm{z})}\right\}>\beta \quad(\mathrm{z} \in \mathrm{D})
$$

for some $\beta(0 \leq \beta<1)$. We denote by $\mathrm{S}^{*}{ }_{\mathrm{w}}(\beta)$ the class of all starlike functions of order $\beta$.

Similarly, a functions $f(z)$ in $S_{w}$ is said to be convex of order $\beta$ if and only if:

$$
\operatorname{Re}\left\{1+\frac{(\mathrm{z}-\mathrm{w}) \mathrm{f}^{\prime \prime}(\mathrm{z})}{\mathrm{f}^{\prime}(\mathrm{z})}\right\}>\beta \quad \mathrm{a}(\mathrm{z} \in \mathrm{D})
$$

for some $\beta(0 \leq \beta<1)$.

It follows from the definitions 3 and 4 that:

Corresponding Author: F. Ghanim, School of Mathematical Sciences, Faculty of Science and Technology, Universiti Kebangsaan Malaysia, Bangi 43600 Selangor D. Ehsan, Malaysia 


$$
\mathrm{f}(\mathrm{z}) \in \mathrm{S}_{\mathrm{W}}^{*}(\beta) \Leftrightarrow \mathrm{zf}^{\prime}(\mathrm{z}) \in \mathrm{C}_{\mathrm{W}}^{*}(\beta)
$$

We denote by $C^{*}{ }_{w}(\beta)$ the class of all convex functions of order $\beta$.

For the function $\mathrm{f}(\mathrm{z})$ in the class $\mathrm{S}_{\mathrm{w}}$, we define:

- $\quad I^{0} f(z)=f(z)$

- $\quad I^{\prime} f(z)=(z-w) f^{\prime}(z)+\frac{2 \alpha}{z-w}$

- $\quad \mathrm{I}^{2} \mathrm{f}(\mathrm{z})=(\mathrm{z}-\mathrm{w})\left(\mathrm{I}^{\mathrm{l} f} \mathrm{z}(\mathrm{z})\right)^{\prime}+\frac{2 \alpha}{\mathrm{z}-\mathrm{W}}$

and for $\mathrm{k}=1,2,3, \ldots$ we can write:

$$
\begin{aligned}
\mathrm{I}^{\mathrm{k}} \mathrm{f}(\mathrm{z}) & =(\mathrm{z}-\mathrm{w})\left(\mathrm{I}^{\mathrm{k}-\mathrm{f}} \mathrm{f}(\mathrm{z})\right)^{\prime}+\frac{2 \alpha}{\mathrm{z}-\mathrm{w}} \\
& =\frac{\alpha}{\mathrm{z}-\mathrm{w}}+\sum_{\mathrm{n}=1}^{\infty} \mathrm{n}^{\mathrm{k}} \mathrm{a}_{\mathrm{n}}(\mathrm{z}-\mathrm{w})^{\mathrm{n}}
\end{aligned}
$$

The differential operator $\mathrm{I}^{*}$ studied extensively by $^{[10,11]}$ and in the case $\mathrm{w}=0$ was given by ${ }^{[9]}$.

We note that the class $S_{0}^{*}(\beta)$ and various other subclasses of $S^{*}{ }_{0}(\beta)$ have been studied rather extensively by ${ }^{[1-8,10-12,16-25]}$.

Next, we will recall each of the following coefficient inequalities associated with the function classes $S^{*}{ }_{w}(k, \beta)$ and $C^{*}{ }_{w}(k, \beta)$ as well as some significant definitions which will contribute to this study.

Definitions and preliminaries: Theorem $A^{[11]}$ if $f \in S_{w}$, given by 2 , satisfies the coefficient inequality:

$$
\sum_{n=1}^{\infty} n^{k}(n+\beta) a_{n} \leq \alpha(1-\beta)
$$

with $\beta(0 \leq \beta<1)$ and $0<\alpha \leq 1$, then $f \in \mathrm{S}_{\mathrm{W}}^{*}(\mathrm{k}, \beta)$.

Theorem B: If $\mathrm{f} \in \mathrm{S}_{\mathrm{W}}$, given by 2, satisfies the coefficient inequality:

$$
\sum_{n=1}^{\infty} n^{k+1}(n+\beta) a_{n} \leq \alpha(1-\beta)
$$

with $\beta(0 \leq \beta<1)$ and $0<\alpha \leq 1$, then $\mathrm{f} \in \mathrm{C}_{\mathrm{W}}^{*}(\mathrm{k}, \beta)$.

Proof: It is easy to check that if:

$$
\mathrm{f}(\mathrm{z}) \in \mathrm{S}_{\mathrm{W}}^{*}(\beta) \Leftrightarrow \mathrm{zf}^{\prime}(\mathrm{z}) \in \mathrm{C}_{\mathrm{W}}^{*}(\beta)
$$

Then we have $\mathrm{f} \in \mathrm{C}_{\mathrm{W}}^{*}(\mathrm{k}, \beta)$. Hence the theorem.

In view of Theorem $A$ and Theorem $B$, we now introduce the subclasses $\mathrm{S}_{\mathrm{w}}^{*}(\beta) \subset \mathrm{ST}_{\mathrm{w}}(\beta)$ $\mathrm{C}_{\mathrm{w}}^{*}(\beta) \subset \mathrm{CV}_{\mathrm{w}}(\beta)$ which consist of functions $\mathrm{f} \in \mathrm{S}_{\mathrm{w}}$ whose Taylor-Maclaurin coefficients $a_{n}$ satisfy the inequalities 3 and 4, respectively.

In our proposed investigation of functions in the classes $S^{*}{ }_{w}(\beta)$ and $C^{*}{ }_{w}(\beta)$ we shall also make use of the following definitions and results.

Definition 1: (Hadamard Product or Convolution). Given two functions $f, g \in S_{w}$ where $f$ is given by 5 and $\mathrm{g}(\mathrm{z})$ is defined by:

$$
g(z)=\frac{\alpha}{z-w}+\sum_{n=1}^{\infty} b_{n}(z-w)^{n}
$$

$\left(b_{n} \geq 0, z \in D\right)$. The Hadamard product (or convolution) $\mathrm{f}^{*} \mathrm{~g}$ is defined (as usual) by:

$$
\begin{aligned}
& (f * g)(z)=\frac{\alpha}{z-w}+\sum_{n=1}^{\infty} a_{n} b_{n} \\
& (z-w)^{n}=(g * f)(z)
\end{aligned}
$$

Definition 2: (Subordination Principle). For two functions $\mathrm{f}$ and $\mathrm{g}$, analytic in $\mathrm{D}$, we say that the function $F(z)$ is subordinate to $g(z)$ in $D$ and write $f$ $\mathrm{f} \prec \mathrm{g}$ or $\mathrm{f}(\mathrm{z}) \prec \mathrm{g}(\mathrm{z})$.

If there exists a Schwarz function $w(z)$, analytic in $\mathrm{D}$ with $\mathrm{w}(0)=0$ and $|\mathrm{w}(\mathrm{z})|<1$ such that $\mathrm{f}(\mathrm{z})=\mathrm{g}(\mathrm{w}(\mathrm{z}))$.

In particular, if the function $g$ is univalent in $\mathrm{D}$, the above subordination is equivalent to $\mathrm{f}(0)=\mathrm{g}(0)$ and $\mathrm{f}(\mathrm{D}) \subset \mathrm{g}(\mathrm{D})$.

Definition 3: (Subordinating Factor Sequence). A sequence $\left\{b_{n}\right\}_{n=1}^{\infty}$ of complex numbers is said to be a subordinating factor sequence if, whenever $\mathrm{f}(\mathrm{z})$ of the form (2) is analytic, univalent and convex in D, we have the subordination given by:

$$
\begin{aligned}
& \sum_{n=1}^{\infty} a_{n} b_{n}(z-w)^{n} \prec f(z) \\
& \left(z \in D, a_{1}=1\right)
\end{aligned}
$$

Theorem C: (cf. Wilf [26]). The sequence $\left\{b_{n}\right\}_{n=1}^{\infty}$ is a subordinating factor sequence if and only if:

$$
\mathfrak{R}\left(1+2 \sum^{\infty} \mathrm{b}_{\mathrm{n}} \mathrm{z}^{\mathrm{n}}\right)>0, \quad(\mathrm{z} \in \mathrm{D})
$$


Subordination results for the classes: $S_{w}^{*}(\beta)$ AND $\mathrm{ST}_{\mathrm{w}}(\beta)$ Our first main result (Theorem 1 below) provides a sharp subordination result involving the function class $\mathrm{S}_{\mathrm{w}}^{*}(\beta)$.

Theorem 1: Let the function $\mathrm{f}$ defined by 2 be in the class $S_{w}^{*}(\beta)$. Also let $\Omega$ denote the familiar class of functions $f \in S_{\mathrm{w}}$ which are also univalent and convex in $D$, then:

$$
\frac{1+\beta}{1+\beta+\alpha-\alpha \beta}(\mathrm{f} * \mathrm{~g})(\mathrm{z}) \prec \mathrm{g}(\mathrm{z})
$$

$(\mathrm{z} \in \mathrm{D}, 0 \leq \beta<1,0<\alpha \leq 1)$ and

$$
\mathfrak{R}(\mathrm{f}(\mathrm{z}))>\frac{1+\beta+\alpha-\alpha \beta}{2(1+\beta)}
$$

The following constant factor in the subordination result (13):

$$
\frac{1+\beta}{1+\beta+\alpha-\alpha \beta}
$$

cannot be replaced by a larger one.

Proof: Let $f \in \mathrm{S}_{\mathrm{w}}^{*}(\beta)$ and suppose that:

$$
\mathrm{g}(\mathrm{z})=\frac{\alpha}{\mathrm{z}-\mathrm{w}}+\sum_{\mathrm{n}=1}^{\infty} \mathrm{c}_{\mathrm{n}}(\mathrm{z}-\mathrm{w})^{\mathrm{n}} \in \Omega
$$

Then we readily have:

$$
\begin{aligned}
& \frac{1+\beta}{1+\beta+\alpha-\alpha \beta}(f * g)(z)=\frac{1+\beta}{1+\beta+\alpha-\alpha \beta} \\
& \left(\frac{\alpha}{z-w}+\sum_{n=1}^{\infty} c_{n} a_{n}(z-w)^{n}\right)
\end{aligned}
$$

Thus, by Definition 3, the subordination result 13 will hold true if:

$$
\left\{\frac{1+\beta}{1+\beta+\alpha-\alpha \beta} a_{n}\right\}_{n=1}^{\infty}
$$

is a subordinating factor sequence (with, of course, $\left.\mathrm{a}_{1}=1\right)$.

In view of Theorem $\mathrm{C}$, this is equivalent to the following inequality:

$$
\underset{(\mathrm{z} \in \mathrm{D})}{\mathfrak{R}\left(1+2 \sum_{\mathrm{n}=1}^{\infty} \frac{1+\beta}{1+\beta+\alpha-\alpha \beta} \mathrm{a}_{\mathrm{n}}(\mathrm{z}-\mathrm{w})^{\mathrm{n}}\right)>0}
$$

Now, $\operatorname{since}(n+\beta),(0 \leq \beta<1)$ is an increasing function of $\mathrm{n}$, we have:

$$
\begin{aligned}
& \Re\left(1+2 \sum_{n=1}^{\infty} \frac{1+\beta}{1+\beta+\alpha-\alpha \beta} a_{n}(z-w)^{n}\right) \\
& =\Re\left(1+\frac{2}{1+\beta+\alpha-\alpha \beta} \sum_{n=1}^{\infty}(1+\beta) a_{n}(z-w)^{n}\right) \\
& \geq 1-\frac{2}{1+\beta+\alpha-\alpha \beta} \sum_{n=1}^{\infty}(n+\beta)\left|a_{n}\right| r^{n} \\
& >1-\frac{2 \alpha(1-\beta)}{1+\beta+\alpha-\alpha \beta} r>0 \\
& (|z-w|=r<1)
\end{aligned}
$$

where we have also made use of the assertion 7 of Theorem A. This evidently proves the inequality 17 and hence also the subordination result 13 asserted by Theorem 1 .

The inequality 14 follows from 7 upon setting:

$$
\begin{aligned}
& \mathrm{g}(\mathrm{z})=\frac{1}{\mathrm{z}-\mathrm{w}}\left(\frac{\alpha}{1-(\mathrm{z}-\mathrm{w})}\right) \\
& =\frac{\alpha}{\mathrm{z}-\mathrm{w}}+\sum_{\mathrm{n}=1}^{\infty}(\mathrm{z}-\mathrm{w})^{\mathrm{n}} \in \Omega
\end{aligned}
$$

Next we consider the function:

$$
\begin{aligned}
& \mathrm{q}(\mathrm{z})=\frac{\alpha}{\mathrm{z}-\mathrm{w}}-\frac{2 \alpha(1-\beta)}{1+\beta+\alpha-\alpha \beta}(\mathrm{z}-\mathrm{w}) \\
& (0 \leq \beta<1)
\end{aligned}
$$

which is a member of the class $S_{w}^{*}(\beta)$. Then, by using 13 , we have:

$$
\begin{aligned}
& \frac{1+\beta}{1+\beta+\alpha-\alpha \beta} \mathrm{q}(\mathrm{z}) \prec \frac{1}{\mathrm{z}-\mathrm{w}}\left(\frac{\alpha}{1-(\mathrm{z}-\mathrm{w})}\right), \\
& (\mathrm{z} \in \mathrm{D})
\end{aligned}
$$

It is also easily verified for the function q (z) defined by 20 that:

$$
\min \left\{\mathfrak{R}\left(\frac{1+\beta}{1+\beta+\alpha-\alpha \beta} \mathrm{q}(\mathrm{z})\right)\right\}=\frac{-\alpha}{2}
$$


which completes the proof of Theorem 1.

Corollary: Let the function $\mathrm{f}$ defined by 2 be in the class $\operatorname{ST}_{\mathrm{W}}(\beta)$. Then the assertions 13 and 14 of Theorem 1 hold true. Furthermore, the following constant factor:

$$
\frac{1+\beta}{1+\beta+\alpha-\alpha \beta}
$$

cannot be replaced by a larger one.

By taking $\alpha=1$ in the above corollary, we obtain.

Corollary: Let the function $\mathrm{f}$ defined by 2 be in the class $\mathrm{ST}_{\mathrm{W}}(\beta)$. Then

$$
\left(\frac{1}{2}(1+\beta)\right)(\mathrm{f} * \mathrm{~g})(\mathrm{z}) \prec \mathrm{g}(\mathrm{z})
$$

and

$$
\mathfrak{R}(\mathrm{f}(\mathrm{z}))>-\frac{1}{1+\beta}
$$

The constant factor $\left(\frac{1}{2}(1+\beta)\right)$ in the subordination result 25 cannot be replaced by a larger one.

Subordination results for the classes: $C_{W}^{*}(\beta)$ and $\mathrm{CV}_{\mathrm{W}}(\beta)$ Our proof of Theorem 2 below is much akin to that of Theorem1. Here we make use of Theorem B in place of Theorem A.

Theorem 2: Let the function $\mathrm{f}$ defined by 2 be in the class $C_{W}^{*}(\beta)$. Then:

$$
\frac{1+\beta}{1+\beta+\alpha-\alpha \beta}(f * g)(z) \prec g(z)
$$

$(\mathrm{z} \in \mathrm{D}, 0 \leq \beta<1,0<\alpha \leq 1)$ and

$$
\mathfrak{R}(\mathrm{f}(\mathrm{z}))>\frac{1+\beta+\alpha-\alpha \beta}{2(1+\beta)}
$$

The following constant factor in the subordination result 25:

$$
\frac{1+\beta}{1+\beta+\alpha-\alpha \beta}
$$

cannot be replaced by a larger one.

Corollary: Let the function $\mathrm{f}$ defined by 2 be in the class $\mathrm{CV}_{\mathrm{W}}(\beta)$. Then the assertions 25 and 26 of Theorem 2 hold true. Furthermore, the following constant factor:

$$
\frac{1+\beta}{1+\beta+\alpha-\alpha \beta}
$$

cannot be replaced by a larger one.

By taking $\alpha=1$ in the above corollary, we obtain.

Corollary: Let the function $\mathrm{f}$ defined by 2 be in the class $\mathrm{CV}_{\mathrm{W}}(\beta)$. Then

$$
\left(\frac{1}{2}(1+\beta)\right)(f * g)(z) \prec g(z)
$$

and

$$
\mathfrak{R}(\mathrm{f}(\mathrm{z}))>-\frac{1}{1+\beta}
$$

The constant factor $\left(\frac{1}{2}(1+\beta)\right)$ in the subordination result 27 cannot be replaced by a larger one.

\section{ACKNOWLEDGEMENT}

The study presented here was supported by Science Fund: 04-01-02-F0425.

\section{REFERENCES}

1. Acu, M. and S. Owa, 2005. On some subclass of univalent functions. J. Inequality Pure Appl. Math., 6: 1-6.

2. Aouf, M.K., 1991. On a certain class of meromorphic univalent functions with positive coefficient. Rend. Mat. Appl., 11: 209-219.

3. Bajpai, S.K., 1977. A note on a class of meromorphic univalent functions, Rev. Roumaine Math. Pure Appl., 22: 295-297.

4. Bhowmik, B. and S. Ponnusamy, 2008. Coefficient inequalities for concave and meromorphically starlike univalent functions, Annales. Polonici Math., 93: 177-186.

5. Bhowmik, B., S. Ponnusamy and K.J. Wirths, 2007. Domains of variability of Laurent coefficients and the convex hull for the family of concave univalent functions. Kodai Math. J., 30: 385-393. 
6. Cho, N.E., S.H. Lee, and S. Owa, 1987. A class of meromorphic univalent functions with positive coefficients. Kobe J. Math., 4: 43-50.

7. Clunie, J., 1959. On meromorphic schlicht functions. J. London Math. Soc., 34: 215-216.

8. Duren, P.L., 1983. Univalent Functions. Grundlehren der Mathematischen Wissenschafen. Vol. 259, Springer- Verlag, Newyork/Berlin/ Heidelberg/Tokyo, pp: 29 and 137.

9. Frasin, B.A. and M. Darus, 2004. On certain meromorphic functions with positive coefficients. South East Asian Bull. Math., 28 : 615-623.

10. Ghanim, F. and M. Darus, 2008. On certain class of analytic function with fixed second positive coefficient. Int. J. Math. Anal., 2: 55-66.

11. Ghanim, F., M. Darus and S. Sivasubramanian, 2007. On new subclass of analytic univalent function. Int. J. Pure Appl. Math., 40: 307-319.

12. Goel, R.M. and N.S. Sohi, 1982. On a class of meromorphic functions. Glas. Mat. Ser., 17: 19-28.

13. Goodman, A.W., 1991. On uniformly starlike functions. J. Math. Anal. Appl., 155: 364-370.

14. Goodman, A.W., 1991. On uniformly convex functions. Ann. Polon. Math., 56: 87-92.

15. Kanas, S. and F. Ronning, 1991. Uniformaly starlike and convex function and other related classes of univalent functions. Ann. Univ. Mariae Curie-Sklodowaska, 53: 95-105.

16. Miller, J., 1970. Convex meromorphic mappings and related functions. Proc. Am. Math. Soc., 25: $220-228$.
17. Mogra, M.L., 1985. T.R. Reddy and O.P. Juneja, Meromorphic univalent functions with positive coefficients. Bull. Aust. Math. Soc., 32: 161-176.

18. Nehari, Z. and E. Netanyahu, 1957. On the coefficients of meromorphic schlicht functions. Proc. Am. Math. Soc., 8: 15-23.

19. Pommerenke, Ch., 1963. On meromorphic starlike functions. Pacific J. Math., 13: 221-235.

20. Pommerenke, Ch., 1962 Uber einige klassen meromorfer schlichter funktionen, Math. Zeitschr., 8: 263-284.

21. Royster, W.C., 1963. Meromorphic starlike multivalent functions. Trans. Am. Math. Soc., 107: 300-308.

22. Srivastava, H.M. and S. Owa, 1992. Current Topics in Analytic Functions Theory. World Scientific, Singapore/New Jersey/ London/ Hong Kong, pp.86 and 429.

23. Uralgaddi, B.A. and M.D. Gangi, 1987. A certain class of meromorphic univalent functions with positive coefficients. Pure Appl. Math. Sci., 26: $75-81$.

24. Uralgaddi, B.A. and C. Somanatha, 1991. New criteria for meromorphic starlike univalent functions. Bull. Aust. Math. Soc., 43: 137-140.

25. Uralgaddi, B.A. and C. Somanatha, 1991. Certain differential operators for meromorphic functions. Houston J. Math., 17: 279-284.

26. Wilf, H.S., 1961. Subordinating factor sequences for convex maps of the unit circle. Proc. Am. Math., 12: 689-693. 